\title{
An Approach to Quantify the Loss Reduction due to Distributed Generation
}

\author{
S B Karajgi \\ Department of Electrical Engineering \\ S.D.M. College of Engineering and Technology, \\ Dharwad,India
}

\author{
Udaykumar R.Y \\ Department of Electrical Engineering \\ National Institute of Technology Karnataka, \\ Surathkal,India
}

\begin{abstract}
Line Loss Reduction is one of the major benefits of Distributed Generation, amongst many others, when incorporated in the Power Distribution System. The quantum of the line loss reduction should be exactly known to assess the effectiveness of the distributed generation. In this paper, the total loss of a practical distribution system is calculated with and without distributed generation and an index, quantifying the total line loss reduction is proposed. Simulation tests have been carried out on a practical distribution system and the proposed index is evaluated for various ratings, locations of distributed generation.
\end{abstract}

\section{Keywords}

Distributed Generation, System Loss Reduction Index.

\section{INTRODUCTION}

The presence of Distributed Generation (DG) has been shown to be beneficial in many respects like voltage profile improvement, line loss reduction, improvement in reliability etc. [1]-[5]. The evaluation of these benefits is very critical in assessing the merit of DG. The quantification of the benefit of line loss reduction was proposed in [6], which evaluated the line losses both with and without DG and the benefit index was defined as the ratio of line loss with DG and that without DG. The subsequent researches [7]-[10], also defined the quantification in a similar way and the benefits of DG were defined. These works, however, considered only the losses in the lines and the quantification was defined for the line losses only. These indices, therefore, do not indicate the loss reduction of the system itself. A practical distribution system consists of several distribution transformers, supplying consumers at low voltage on the secondary side. The losses occurring in these transformers and the line losses of the secondary low voltage distribution system should also be considered to arrive at the overall loss reduction of the system. In this paper, a practical distribution system, supplying a number of consumers at low voltage, is considered. The losses occurring in the transformers and the low voltage distribution lines have been considered and the benefit of DG in respect of total loss is evaluated.

\section{DESCRIPTION OF THE SYSTEM}

A simple distribution system shown in fig 1, is considered for analysis. The system consists a number of identical distribution transformers, the secondary of which supply power to the consumers at low voltage. The core loss of each transformer is represented by Pc.

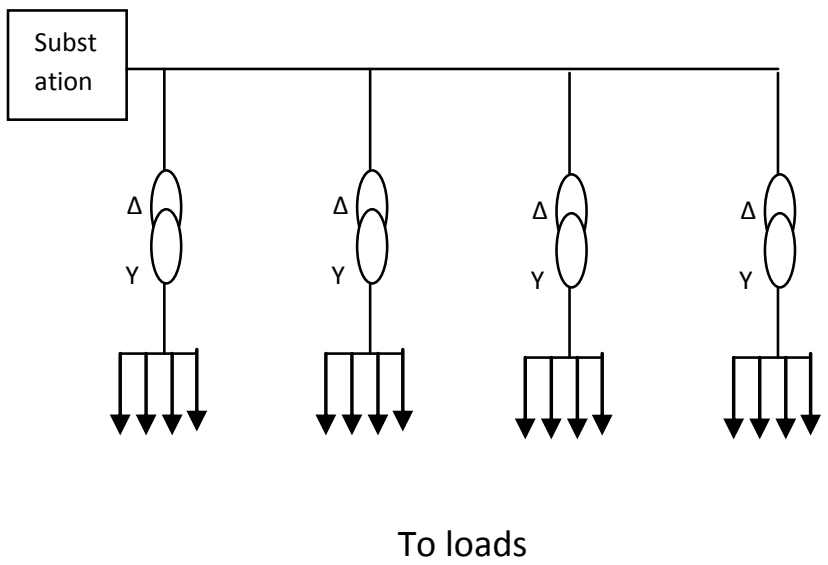

Fig 1: The single line diagram of a standard distribution system.

For simplicity, the following assumptions are made.

- All loads are modeled as constant current loads, drawing the same current irrespective of the respective voltages.

- The core losses of the transformers remain constant at a value depending on the rating.

- All loads draw the power at a power factor of 0.8 lagging.

- DG unit is capable of supplying power at both leading and lagging power factors.

- The copper losses of the distribution transformer are of small value and are neglected

\section{LOSS REDUCTION ANALYSIS}

The total loss of the distribution system without DG is given by 
$\operatorname{Loss}_{\text {Syst w/o DG }}=\sum_{i=1}^{N-1} I_{i}^{2} r l_{i}+\sum_{i=1}^{N-1}\left(P_{C_{i}}+P_{L V_{i}}\right)$

Where $\mathrm{I}$ is the current flowing through $\mathrm{i}^{\text {th }}$ segment, $\mathrm{L}_{\mathrm{i}}$ is the length of $i^{\text {th }}$ segment, $r$ is the resistance of line in ohms per unit length., $P_{C_{i}}$ is the core loss of $i^{\text {th }}$ transformer, $P_{L V_{i}}$ is the Losses on the low voltage side of the $\mathrm{i}^{\text {th }}$ transformer and $\mathrm{N}$ is the number of busses in the system.

In order to determine the losses of the system, the core loss of each transformer and the LV side losses on each transformer must be known. It is evident from the above equation that the total losses can be reduced only by reducing the first term of equation (4.1) which represents the feeder line losses, since the other term representing the core loss and the LV side loss of each transformer remain same independent of the presence of DG.

With the inclusion of DG, the currents in the feeder segments will be redistributed. If a DG unit is inserted at $\mathrm{K}^{\text {th }}$ bus, the feeder segments up to bus $\mathrm{K}$ will carry the difference of the initial current and the injected current by the DG unit. The segments beyond $\mathrm{K}$ will continue to carry the same currents. The total loss of the feeder with DG is the given by

$\operatorname{Loss}_{\text {Feed w DG }}=\sum_{i=1}^{K-1}\left(I_{i}-I_{G}\right)^{2} r l_{i}+\sum_{i=K}^{N-1} I_{i}^{2} r l_{i}$

Where $I_{G}$ is the current injected by the DG unit and $I_{i}$ remains the same at earlier value.

The total loss of the distribution system with DG is now

$\operatorname{LosS}_{\text {SystwDG }}=$

$\sum_{i=1}^{K-1}\left(I_{i}-I_{G}\right)^{2} r l_{i}+\sum_{i=K}^{N-1} I_{i}^{2} r l_{i}+\sum_{i=1}^{N-1}\left(P_{C_{i}}+P_{L V_{i}}\right)(3)$

A factor, System Loss Reduction Index (SLRI), which quantifies the loss reduction with the insertion of DG is defined as

SLRI $=$

Loss in the system with DG

Loss in the system without DG
$=$

$$
\frac{\sum_{i=1}^{K-1}\left(I_{i}-I_{G}\right)^{2} r l_{i}+\sum_{i=K}^{N-1} I_{i}^{2} r l_{i}+\sum_{i=1}^{N-1}\left(P_{C_{i}}+P_{L V_{i}}\right)}{\sum_{i=1}^{K-1}\left(I_{i}-I_{G}\right)^{2} r l_{i}+\sum_{i=K}^{N-1} I_{i}^{2} r l_{i}}
$$

The distribution system loss can be rewritten as

$$
\begin{aligned}
& \sum_{i=1}^{\operatorname{Loss}_{\mathrm{SyswG}}=}\left(I_{i}^{2}-2 I_{i} I_{G}+I_{G}\right)^{2} r l_{i}+\sum_{i=K}^{N-1} I_{i}^{2} r l_{i}+\sum_{i=1}^{N-1}\left(P_{C_{i}}+P_{L V_{i}}\right) \\
& =\sum_{i=1}^{K-1}\left(I_{G}^{2}-2 I_{i} I_{G}\right) r l_{i}+\sum_{i=1}^{N-1} I_{i}^{2} r l_{i}+\sum_{i=1}^{N-1}\left(P_{C_{i}}+P_{L V_{i}}\right)
\end{aligned}
$$

Substituting equation (2) in equation (5) we get

$\operatorname{Loss}_{\text {SystwDG }}=\operatorname{Loss}_{\text {Systw/o DG }}+\sum_{i=1}^{K-1}\left(I_{G}^{2}-2 I_{i} I_{G}\right) r l_{i}$

On simplification, following equation is obtained

$$
\begin{aligned}
\text { Loss }_{\text {Syst w DG }}= & \text { Loss }_{\text {Syst w/o DG }}+\sum_{i=1}^{K-1} I_{G}\left(I_{G}-2 I_{i}\right) r l_{i} \\
& =\text { Loss }_{\text {Syst w/o DG }}+\mathrm{K}_{\text {loss }} \mathrm{I}_{\mathrm{G}}
\end{aligned}
$$

Where $\mathrm{K}_{\text {loss }}$ is the loss factor given by

$$
\mathrm{K}_{\mathrm{loss}}=\sum_{i=1}^{K-1}\left(I_{G}-2 I_{i}\right) r l_{i}
$$

The SLRI is now obtained as

$$
\text { SLRI }=\frac{\text { Loss }_{\text {Syst w/o DG }}+\mathrm{K}_{\text {loss }} \mathrm{I}_{\mathrm{G}}}{\text { Loss Syst w/o DG }}
$$

If $\mathrm{SLRI}<1$, the DG has reduced the losses and is beneficial $=1$ the DG has not made any changes in the system.

$$
>1 \text {, the DG has introduced more losses in the system. }
$$

It is clear from equation (9) that the loss factor $\mathrm{K}_{\text {loss }}$ must be negative if DG is expected to reduce the losses in the system. Since the loss factor depends on the summation of the difference between the injected DG current and twice the feeder segment current, it attains maximum negative value when it is installed at the remote end $\mathrm{N}$. 
The Loss factor and thus the SLRI are greatly influenced by the power factors of the DG unit. In case the unit is operating at unity power factor, all the reactive power required by the load is supplied by the source and hence the there may not be any appreciable decrease of line current supplied by the source leading to higher losses and thus low SLRI.

\section{SIMULATION TESTS}

A practical 36 bus, $11 \mathrm{KV}$ distribution feeder shown in fig 2, is considered. The system consists of 35 distribution transformers with various ratings. The details of the distribution transformers are given in table 1. The base MVA used in the study is 5 MVA. The conductor used is Rabbit with resistance of $0.0030173 \mathrm{pu} / \mathrm{km}$ and reactance of 0 . $0020143 \mathrm{pu} / \mathrm{km}$. The lengths of the feeder segments are given in table 2. The total connected load on the system is 2300 KVA and the peak demand for the year is $2000 \mathrm{KVA}$ at a pf of 0.8 lag. The connected loads on the transformers are listed in table 3.

The system consists of two DG units described below.

1. DG1, of rating $270 \mathrm{KW}$, connected at node No 26 , shown with arrow mark in the fig. 2 .

2. DG2, of rating $800 \mathrm{KW}$ connected at node No 41, shown with arrow mark in fig 2 .
Table 1. Details of transformers in the system

\begin{tabular}{|c|c|c|c|}
\hline Rating (KVA) & 63 & 100 & 250 \\
\hline Number & 16 & 18 & 1 \\
\hline No Load Losses (Watts) & 180 & 260 & 470 \\
\hline \% Impedance & 4.5 & 4.5 & 4.5 \\
\hline
\end{tabular}

Fig 2: Single line Diagram of the distribution system

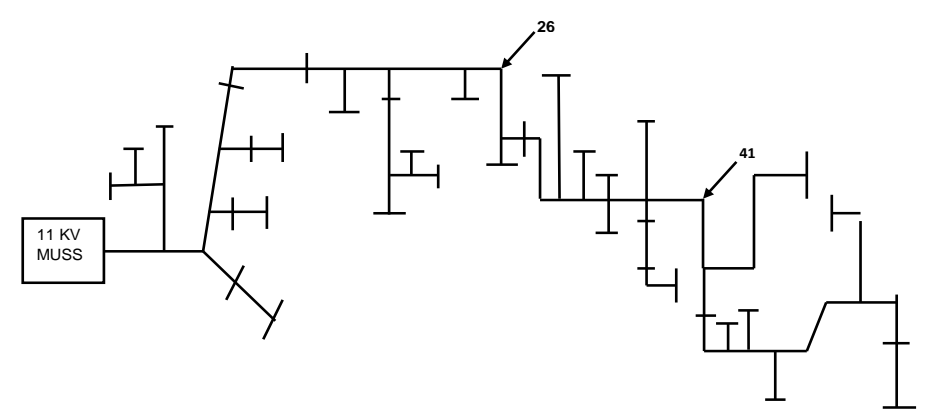

Table 2. Distribution System Line Data

\begin{tabular}{|c|c|c|c|c|c|c|c|c|}
\hline from & $\begin{array}{c}\text { To } \\
\text { node }\end{array}$ & $\begin{array}{r}\text { Length } \\
\text { (mtrs) }\end{array}$ & $\begin{array}{l}\text { From } \\
\text { node }\end{array}$ & $\begin{array}{c}\text { To } \\
\text { node }\end{array}$ & $\begin{array}{r}\text { Length } \\
\text { (mtrs) }\end{array}$ & $\begin{array}{l}\text { From } \\
\text { node }\end{array}$ & $\begin{array}{c}\text { To } \\
\text { node }\end{array}$ & $\begin{array}{c}\text { Length } \\
\text { (mtrs) }\end{array}$ \\
\hline 1 & 2 & 300 & 18 & 19 & 60 & 39 & 40 & 80 \\
\hline 2 & 3 & 80 & 18 & 20 & 80 & 37 & 38 & 160 \\
\hline 3 & 4 & 80 & 20 & 21 & 60 & 37 & 39 & 80 \\
\hline 4 & 5 & 60 & 21 & 22 & 80 & 39 & 40 & 80 \\
\hline 5 & 6 & 60 & 22 & 23 & 60 & 40 & 41 & 80 \\
\hline 2 & 7 & 120 & 22 & 24 & 60 & 41 & 42 & 120 \\
\hline 7 & 8 & 60 & 24 & 25 & 60 & 41 & 43 & 60 \\
\hline 8 & 9 & 60 & 20 & 26 & 80 & 43 & 44 & 260 \\
\hline 7 & 10 & 120 & 26 & 27 & 80 & 44 & 45 & 80 \\
\hline 10 & 11 & 60 & 26 & 28 & 120 & 44 & 46 & 60 \\
\hline 11 & 12 & 60 & 28 & 29 & 40 & 46 & 47 & 60 \\
\hline 10 & 13 & 120 & 29 & 30 & 360 & 48 & 48 & 180 \\
\hline 13 & 14 & 60 & 30 & 31 & 80 & 48 & 49 & 60 \\
\hline 14 & 15 & 60 & 30 & 32 & 80 & 48 & 50 & 290 \\
\hline 13 & 16 & 120 & 32 & 33 & 90 & 50 & 51 & 90 \\
\hline 16 & 17 & 90 & 32 & 34 & 90 & 50 & 52 & 300 \\
\hline 17 & 18 & 400 & 34 & 37 & 90 & 52 & 53 & 60 \\
\hline
\end{tabular}


Table 3. Details of the connected loads.

\begin{tabular}{|c|c|c|c|}
\hline $\begin{array}{l}\text { Transformer } \\
\text { No }\end{array}$ & $\begin{array}{ll}\text { Load in } \\
\text { KVA }\end{array}$ & $\begin{array}{l}\text { Transformer } \\
\text { No }\end{array}$ & $\begin{array}{l}\text { Load in } \\
\text { KVA }\end{array}$ \\
\hline 1 & 61 & 19 & 61 \\
\hline 2 & 61 & 20 & 61 \\
\hline 3 & 38 & 21 & 61 \\
\hline 4 & 38 & 22 & 38 \\
\hline 5 & 38 & 23 & 38 \\
\hline 6 & 38 & 24 & 61 \\
\hline 7 & 38 & 25 & 61 \\
\hline 8 & 38 & 26 & 38 \\
\hline 9 & 38 & 27 & 38 \\
\hline 10 & 61 & 28 & 61 \\
\hline 11 & 38 & 29 & 61 \\
\hline 12 & 61 & 30 & 61 \\
\hline 13 & 61 & 31 & 61 \\
\hline 14 & 38 & 32 & 38 \\
\hline 15 & 61 & 33 & 38 \\
\hline 16 & 38 & 34 & 61 \\
\hline 17 & 61 & 35 & 153 \\
\hline 18 & 61 & & \\
\hline
\end{tabular}

\section{METHOD OF STUDY}

Following steps are followed to evaluate the impacts of DG on the system loss reduction and also to quantify the proposed index.

- The power outputs of both DG1 and DG2 are fixed.

- The details of the distribution system are collected and the system is simulated using CYMEDIST computer simulation program and the DG units are incorporated in the simulated system.

- Load flow studies are conducted for all the specified cases and the results are obtained.

- The results are analyzed and the impacts of DG on the loss reduction are evaluated.
Specific cases considered for study:

The impact of DG in respect of Line Loss Improvement is studied with and without DG in the system.

The operating power factor of DG1 is kept constant at unity and that of DG2 is varied from 0.8 lag, 0.9 lag, unity, 0.9 lead and 0.8 lead. While carrying out the tests, the following assumptions are made.

- $\quad$ All the loads draw power at 0.8 lagging.

- The loads on the low voltage side are distributed over line of length 300 mtrs.

- The core losses of the transformers remain constant at their rated value.

\section{RESULTS}

The simulation results are given in figure 3 . These results reveal that the inclusion of DG reduce the line losses as expected. It can be shown from the graphs that, SLRI decreases marginally, since the core losses of the transformers and the LV side losses remain constant being independent of the presence of DG. This is an improvement over the index derived in [6], which considered only the feeder line losses. It can also be seen that with the increase in the DG output, SLRI, decrease but again show an increasing trend after a threshold value e.g. as the power output is increased the SLRI starts increasing as shown in fig.4. This is because the system receives more power from DG than required and hence the line loss increase appreciably. This should be considered before fixing up the value of DG output. Under such a case, one DG unit can be switched off so that the advantage of lower SLRI can be enjoyed.

The operating power factor of DG also influences the SLRI. It is very clear from the fig 5 that SLRI has lower values with DG operating at lagging power factor and increase under leading power factor. This is because the DG unit absorbs reactive power from the lines under leading power factor. Further, it can be seen that the index may exceed unity, indicating that the presence of DG has increased the line losses than decreasing it. This factor should be considered while fixing the operating power factor of DG.

The variation of loss factor is shown in fig. 6. It is clear from the figure the Loss Factor remains fairly constant and hence 
the loss reduction depends mainly on the current injected by the DG unit. When $I_{G}$ is more than $I_{L}$, loss factor becomes positive and the total losses in the system increase, leading SLRI to acquire a value greater than one.

The location of DG is also very critical in deciding the loss reduction. It is evident from figure 7 , that SLRI show a decreasing trend when DG is located away from the substation. This issue should be considered before installing DG in the system.

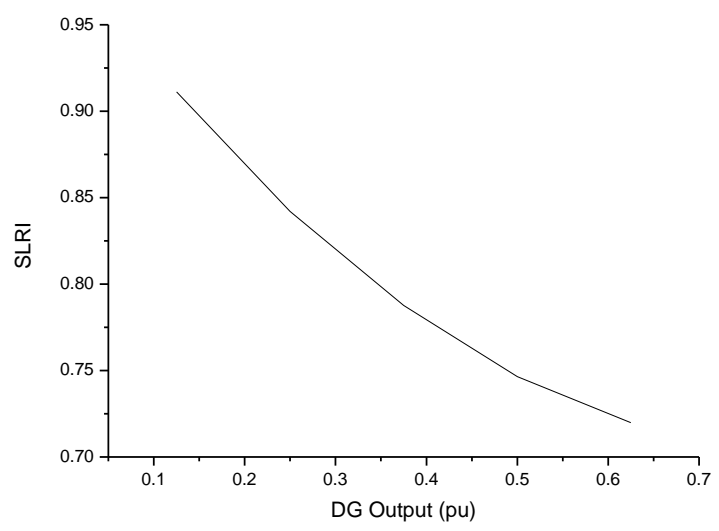

Fig 3: Variation of SLRI with DG Output

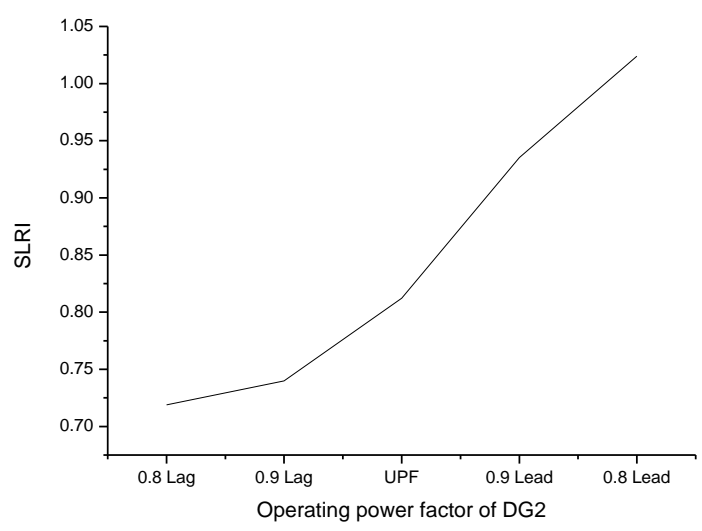

Fig 4: Variation of SLRI with operating power factor of DG

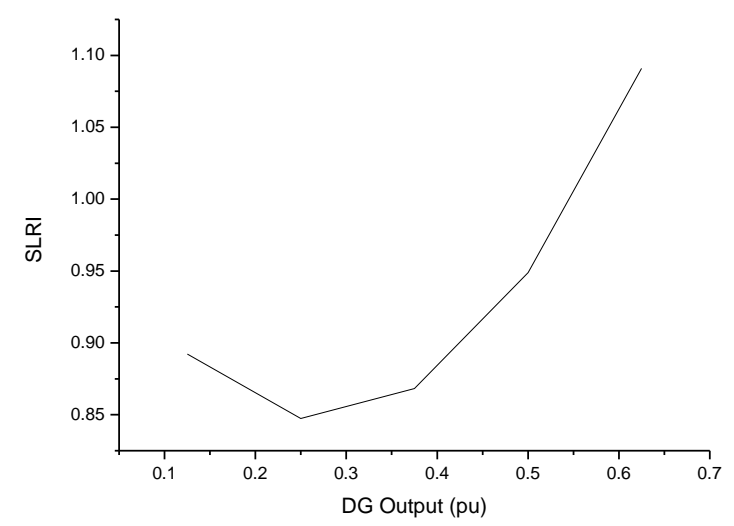

Fig 5: Variation of SLRI with high penetration of DG

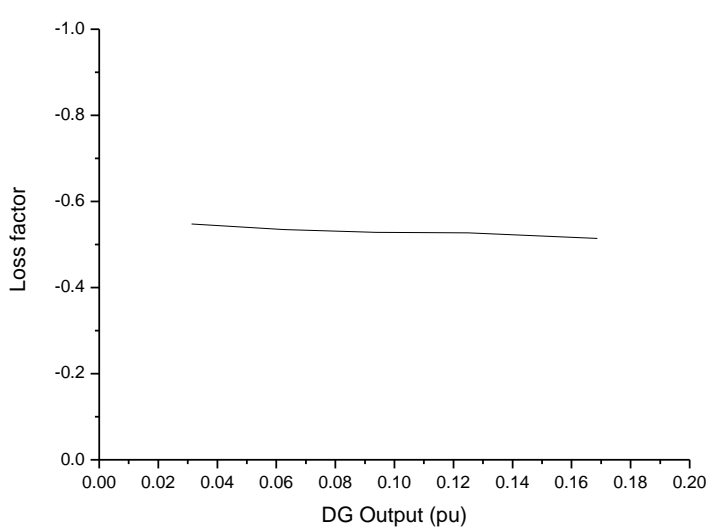

Fig 6: Variation of Loss Factor with DG output.

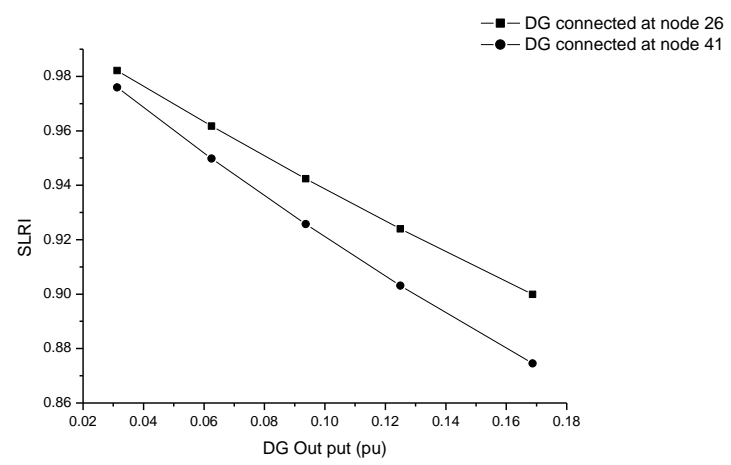

Fig 7: Variation of SLRI with the same DG connected at two different locations. 


\section{CONCLUSION}

The simulation results show that the inclusion of DG, marginally reduce the losses in a distribution system. This is because; the line losses form only a minor part of the distribution system losses and the DG can reduce only the line losses. The other losses viz. the transformer losses and the LV side distribution losses remain unaltered. Hence this fact should be considered before installing a DG into a system.

\section{REFERENCES}

[1] T. Ackermann, G. Andersson, and L. Soder, "Distributed generation: A definition," Elect. Power Syst. Res., vol. 57, pp. 195-204, 2001.

[2] N. Hadjsaid, J. Canard, and F. Dumas, "Dispersed generation impact on distribution networks," IEEE Comput. Appl. Power, vol. 12, no. 2, pp. 22-28, Apr. 1999.

[3] Peter. Daly, “ Understanding the potential Benefits of DG on Power Delivery System”, a paper presented at Rural Electric Power conference 2001, Little Rock, Arkansas, 2001.

[4] Ahmed Azmy, " Impact of DG on the Stability of Electrical Power Systems", ", IEEE Trans. On Power Delivery, 2005, pp $1-8$
[5] E. Vidyasagar, P.V.N.Prasad, "Impact of DG on Radial Distribution System Reliability", in 15th National Power System Conference Conference (NPSC), IIT Bombay 2008, pp 467-472

[6] P. Chiradeja, "Benefit of distributed generation: A line loss reduction analysis," in Proc. IEEE-Power Eng. Soc. Transmission and Distribution Conf. Exhib.: Asia and Pacific, Dalian, China, Aug. 15-17, 2005.

[7] Chiradeja, Ramkumar, "An Approach to quantify the Benefits of Distrributed Generation Systems", IEEE trans. On Energy Conversion, Vol. 19, Dec 2004, pp 764 -773 .

[8] M.A.Kashem, M.Negnevitsky, G.Ledwich , " Distributed Generation for minimization of power losses in distribution systems " , IEEE conference 2006

[9] Hugo A. Gil, Geza Joos, " Models for Quantifying the Economic Benefits of Distributed Generation", IEEE TRANSACTIONS ON POWER SYSTEMS, VOL. 23, NO. 2, MAY 2008,pp327-335

[10] A.Kazemi, and M.Sadeghi," Sitting and Sizing of Distributed Generation for Loss Reduction", Proc. Of Power and Energy Engineering Conference, APPEEC, 2009, Asia-Pacific, pp 1-4. 